\title{
Memories of Professor Kenji Mori, the Giant of Pheromone Synthesis
}

\author{
Hirosato Takikawa ${ }^{1} \mathbb{D}$
}

Received: 10 October 2021 / Revised: 10 October 2021 / Accepted: 17 October 2021 / Published online: 30 October 2021

(c) The Author(s), under exclusive licence to Springer Science+Business Media, LLC, part of Springer Nature 2021

Professor Kenji Mori, the 9th president of the ISCE and professor emeritus of the University of Tokyo, passed away on Apr. 16, 2019, at the age of 84 due to myocardial infarction. As many readers of this journal may know, Professor Mori was an unparalleled synthetic organic chemist who left an indelible mark on the world of chemical ecology through his work on pheromone synthesis.

In Japan, there is a proverb that goes, "The worse the child, the cuter he is," and I believe that this proverb describes the relationship between Mori-sensei and myself very well. While, of course, Mori-sensei and I are not really father and son, but I feel that I have grown up under his warm guidance. Therefore, it is a great honor for me to be a professor in the laboratory where Mori-sensei initiated and developed his work on pheromone synthesis. Because of this relationship, I first learned of the seriousness of his condition on Nov. 28, 2018, shortly after he was diagnosed with terminal cancer. However, at that time, Mori-sensei appeared to be so healthy, with his passion for science continuing to sparkle, that it was hard to believe that he had terminal cancer. However, on Jan. 24, 2019, he collapsed following a myocardial infarction that was likely caused due to his anti-cancer drug treatment. After that, his health deteriorated day by day, but his passion for chemistry was in no way diminish, and he continued to write various scientific papers. Unfortunately, much to our dismay, he had a second heart attack and finally passed away on the morning of Apr. 16, 2019. Since Professor Wittko Francke (who sadly passed away last year), the 6th president of the ISCE and a close friend of Mori-sensei, had already written an elegant and fraternal obituary (Francke 2019), I decided to write this one from the perspective of a disciple.

Mori-sensei's career as an organic chemist began with the synthesis of gibberellin, when he achieved the first synthesis

Hirosato Takikawa

atakikawa@mail.ecc.u-tokyo.ac.jp

1 Department of Applied Biological Chemistry, Graduate School of Agricultural and Life Sciences, The University of Tokyo, 1-1-1 Yayoi, Bunkyo-ku, Tokyo 113-8657, Japan in Dec.1967 (Mori and others 1968). Following this monumental achievement, Mori-sensei became recognized as a rising star in the field of synthetic organic chemistry. Moreover, it was an important turning point that determined the direction of his subsequent research. According to Morisensei, Professor Kei Arima, a world-famous microbiologist, remarked, "Dr. Mori, congratulations on completing the synthesis of gibberellin. But you spent nine years on it. Don't forget that the fungus Gibberella fujikuroi makes gibberellins in a couple of days." At that point, Mori-sensei began to seriously question what he should be doing as a synthetic organic chemist. His decision was to begin his research on insect pheromone synthesis (Mori 1974). The serial number of his Pheromone Synthesis Series reached 265 (Ohkubo and others 2020), a number that eloquently illustrates his astonishing productivity. However, what makes his Pheromone Synthesis Series a truly great achievement is that the results have shown the world that the relationship between stereochemistry and the biological activity in bioactive substances is not always simple. In fact, prior to his series of studies, it was believed that when a bioactive molecule was chiral, only one enantiomer or stereoisomer was significant, while others were meaningless. This belief became somewhat dogma, and the overwhelming majority of scientists did not question it. However, Mori-sensei's research on the synthesis of optically active insect pheromones presented the world with a series of examples that deviated from this dogma claim. This marked a great achievement that encouraged the scientific community to reaffirm the notion that "the natural world is truly diverse!".

Normally, I would perhaps have chosen to simply list various examples of Mori-sensei's brilliant achievements; however, here I would like to share one episode from his last days that clearly shows how he lived his life as a scientist. As some of you may know, in 2003, Mori-sensei made a wonderful comeback as an experimental chemist at the age of 68 , and from that point on, he could be seen standings in front of the laboratory bench conducting experiments by himself. Amazingly, even after being told that he had only one year to live, his daily life remained unchanged. His last synthetic 
study on gomadalactone, the sex pheromone of Anoplophora malasiaca, was published shortly after his death (Pheromone Synthesis 264, Mori 2019). What I would like to share with you is an episode that occurred during the writing process of this paper. I had been asked to assist him in submitting this study, his last self-authored paper, and I had a chance to check the manuscript before submission. During the process, I had a question regarding the structure of one of the intermediates, and when I asked him about it, he replied "I know it's controversial, but I didn't have time to clarify it." I thus asked, "Can we do the NOE experiment now?" to which he replied, "All the samples are still there. I've organized them myself, so they are definitely in the fridge. Just get on with it." I thus immediately contacted the people at Toyo Gosei Co., Ltd., where his laboratory was located at the time, and asked them to send me the samples. It was in mid-March, and I was really surprised to find that all the samples sent to me were perfectly organized. This is because his last experiment was done on Jan. 22, a few days before his myocardial infarction, and he must have had little time to organize his samples. Incidentally, the writing on the label was definitely his. Thus, we found the sample we wanted and were able to solve the structural problem by observing the NOEs. What made it possible to solve the problem quickly was to keep all the experimental data and synthetic samples properly organized and ready for re-evaluation and re-analysis. Who else could do such a thing as an 83-year-old man with terminal cancer? In hindsight, this series of events may have been his last lesson to me. "This is how an experimental scientist should be." In other words, Mori-sensei loved experimental science from the bottom of his heart, always faced his experiments and results with sincerity, and was honest regarding the data and samples. That was the core essence of Mori's science, and I believe that Mori-sensei continued to run as hard as he could on the path he believed in until his final moments.
Lastly, I would like to mention Mori-sensei's funeral, which was held, according to his last wishes, at the church he used to attend on Apr. 19, a suitable sunny day. The funeral of this unparalleled organic chemist and chemical ecologist was so well attended that the chapel and conference rooms were overflowing and the church courtyard was filled with people. I truly believe that this was the funeral that Morisensei, who loved cheerful and lively things, had envisioned.

One year and eight months after Mori-sensei passed away, Professor Francke, unfortunately, also lost his life following COVID-19-related complications. I sincerely hope that these two giants, who were, in fact, the best of friends, will continue to watch over the development of the ISCE.

\section{References}

Francke W (2019) Professor Kenji Mori, 21 March 1935-16 April 2019. J Chem Ecol 45: 808-809

Mori K, Shiozaki M, Itaya N, Ogawa T, Matsui M, Sumiki Y (1968) Synthesis of substances related to Gibberellins part 18. Total synthesis of ( \pm )-Gibberellins $\mathrm{A}_{2}, \mathrm{~A}_{4}, \mathrm{~A}_{9}$, and $\mathrm{A}_{10}$. Tetrahedron Lett. $2183-2188$

Mori K (1974) Pheromone synthesis part 1. Absolute configuration of (-)-14-Methylhexadec-8-cis-en-1-ol and methyl (-)-14-methylhexadec-8-cis-enoate, the sex pheromone of female dermestid beetle. Tetrahedron 30:3817-3820

Mori K (2019) Pheromone synthesis. Part 264: Synthesis of the core 3-oxabicyclo[3.3.0]octane structures of gomadalactones A, B and $\mathrm{C}$, the components of the contact sex pheromone of the whitespotted longicorn beetle Anoplophora Malasiaca. Tetrahedron 75:3387-3398

Ohkubo Y, Akasaka K, Masuda Y, Konishi S, Yang CY, Takikawa H, Mori K (2020) Pheromone synthesis. Part 265: Synthesis and stereochemical composition of two pheromonal compounds of the female Korean apricot wasp, Eurytoma maslovskii. Tetrahedron 76: 131410 